\title{
CONTRARREFERENCIAMENTO HOSPITALAR: TENTATIVA DE LIGAÇÃO DAS REDES DE CUIDADO EM PROL DA SAÚDE DO USUÁRIO
}

\author{
Thales Plagens Franco ${ }^{1}$; André Luis Volmer ${ }^{2}$
}

\section{RESUMO}

O processo de contrarreferenciamento visa garantir a continuidade do cuidado, pensando o sujeito em sua singularidade. Diante a isto, foi elaborado um fluxograma de contrarreferência para ordenar o momento da alta hospitalar, visando assegurar o cuidado integral ao paciente. A partir da experiência num hospital no interior do estado do Rio Grande do Sul, foi observada a adesão da equipe à proposta, mesmo que inicialmente com alguma resistência em aceitar e compreender a nova forma de organização; é possível inferir que a ideia necessita indispensavelmente do empenho e senso crítico de todos profissionais envolvidos, uma vez que acompanham multidisciplinarmente os pacientes.

Palavras-chave: Contrarreferência; Cuidado integral; Hospital.

Eixo Temático: Atenção Integral e Promoção à Saúde - AIPS

\section{INTRODUÇÃO}

A cada dia mais são constantes as internações hospitalares de usuários/pacientes tanto por agravos de saúde de lógica aguda, assim como por causas crônicas. Neste sentido, os adoecimentos por agudização são repentinos e ocorrem de forma súbita, ocasionando a emergência de sintomas que necessitam de auxílio e de cuidados médicos imediatos. Por outro lado, os adoecimentos crônicos já são doenças que foram anteriormente diagnosticadas, mas que necessitam de cuidados contínuos e tratamento personalizado conforme a doença e poderá o sujeito, portador de tal, por diversos motivos desestabilizar o quadro clínico e

\footnotetext{
${ }^{1}$ Psicólogo residente em RMS - Reabilitação Física/UFN - thalesplagens@hotmail.com

2 Psicólogo Hospitalar do Hospital Casa de Saúde - andreluisvolmer@gmail.com
} 


\section{PUFN}

agudizar os sintomas necessitando de hospitalização clínica para a retomada e estabilização dos sintomas e ajuste de tratamento (BRASIL, 2019).

Sabendo-se destes fatores, torna-se necessário refletir e conhecer os caminhos que os sujeitos percorrem até chegar ao hospital. Tais caminhos são chamados de fluxos de rede de cuidado, que são organizados em três camadas, que envolvem serviços que estão próximos do sujeito, na comunidade, assim como especialidades clínicas e serviços que oferecem maior suporte, como no caso dos hospitais.

Esta organização da rede de cuidado é denominada por Eugênio Vilaça Mendes (2011), por rede de atenção, que se subdivide em três níveis: Atenção primária à saúde, composta por serviços de saúde básicos e como presume-se, seria o primeiro serviço em que o sujeito teria contato em caso de alguma questão de saúde ou para monitoramento desta. Serviço que possui proximidade e conhece as situações das famílias, suas rotinas, costumes e hábitos, além de reconhecer e de atualizar a epidemiologia local para uma melhor resposta às necessidades de saúde daquela população. São exemplos, desta modalidade de serviço, as Unidades Básicas de Saúde (UBS), as Estratégias de Saúde da Família (ESF).

A atenção de nível secundário, segundo Mendes ( 2011) está associada aos níveis de especialidades médicas. Tais ofertas de atendimento são disponibilizadas em ambulatórios municipais e regionais, que a partir de uma conexão com a atenção primária acolhe as demandas para garantir um atendimento mais personalizado e resolutivo conforme for o grau da situação problema de adoecimento.

Já a atenção terciária à saúde abarca os níveis de maior cuidado e atenção às situações problemas de adoecimento. Tais espaços de saúde oferecem maior monitoramento, infraestrutura, além de medicações com maior eficácia, em que são exemplos os hospitais (MENDES, 2011).

Diante disso, e sabendo dessa dinâmica das redes de atenção à saúde, conforme discutido por Mendes (2011), não basta apenas deferir que a rede já está posta e que funcionará sem maiores entraves. Pelo contrário, cabe a necessidade de levantar tal problemática e pensar a construção e a produção de uma rede de 
cuidado viva, que é executada e praticada pelos sujeitos nas suas mais variadas singularidades, lugares e espaços de saúde.

\section{METODOLOGIA}

O presente estudo trata-se de uma pesquisa bibliográfica, sendo desenvolvido com materiais já elaborados presente em artigos científicos. Segundo Gil (2018), tal método contribui para que o pesquisador consiga uma maior compreensão sobre o tema a ser desenvolvido, servindo também como auxílio na construção das hipóteses e reflexões.

Assim, partindo-se de um contexto hospitalar se faz necessário olhar para a produção e a articulação deste com a rede de cuidado através da elaboração do processo de contrarreferenciamento personalizado de todos os casos clínicos que adentram ao hospital. Assim, o objeto deste estudo, propõe refletir a partir da literatura, da realidade prática e vivências de um residente em reabilitação física, em uma unidade clínica de um hospital no interior do estado do Rio Grande do Sul, a elaboração de um fluxograma para o estabelecimento, efetivação de processos e a conexão de pontos de atenção e cuidado à saúde em prol das respostas às situações problemas de adoecimento dos usuários e continuidade do cuidado.

\section{RESULTADOS E DISCUSSÕES}

\section{1 - A contrarreferência personalizada e a garantia do cuidado integral}

Foram observados os processos de alta hospitalar de usuários adultos e idosos internados na unidade clínica com diagnósticos variados, como covid 19, póscovid, cirrose, ascite, pneumonias, Acidente Vascular Cerebral (AVC), Acidente Vascular Encefálico (AVE), infecções do trato urinário (ITU), erisipela, pielonefrite, HIV/Aids, neurossífilis, tuberculose, agravos por descompensação de hipertensão arterial sistêmica e diabetes. A faixa etária média dos usuários variou de 55 a 80 anos de ambos os sexos.

A alta hospitalar ocorre todos os dias, tanto no turno da manhã, quanto no turno da tarde, não ocorrendo no turno da noite. Para que o processo de 
contrarreferenciamento ocorra e cumpra com suas finalidades, que estão em torno da continuidade do cuidado ao paciente, foi elaborado um fluxo de responsabilidades desempenhadas pela equipe multiprofissional hospitalar, em que cada profissional possui participação e corresponsabilização com este processo.

Sendo assim, segue os dez passos do referido fluxograma de contrarreferenciamento (anexo 1): $1^{\circ}$ - preenchimento da planilha de previsão de alta clínica (anexo 2); $2^{\circ}$ - o médico compartilha a planilha com o enfermeiro da unidade; $3^{\circ}$ - enfermeiro repassa as informações para a dupla de residentes responsáveis pelas contrarreferências daquela semana conforme escala; $4^{\circ}$ - os responsáveis pela semana agendam e devolvem ao médico, a data e horários do agendamento para personalização da contrarreferência; $5^{\circ}$ - médicos preenchem as três vias, para cada serviço encaminhado, posteriormente entregando para o enfermeiro do turno; $6^{\circ}$ - enfermeiro recebe as vias, verifica se está devidamente preenchida e agendada e faz a divisão das contrarreferências; $7^{\circ}$ - enfermeiro faz a divisão: primeira via para o paciente, segunda via para a secretária e a terceira via para o prontuário; $8^{\circ}$ - enfermeiro entrega ao paciente a contrarreferência, sumário de alta e a liberação de alta clínica; $9^{\circ}$ - residentes, conforme escala, fazem o envio de e-mail para as UBS, ESF e demais serviços de saúde para formalizar o contrarreferenciamento e $10^{\circ}$ - residentes e equipe multiprofissional, montam 0 relatório mensal de contrarreferenciamentos efetivados ao longo do mês.

A efetivação deste processo demanda muita organização e é visto que a logística envolve muitos profissionais do serviço; a comunicação efetiva e o trabalho em equipe se tornam fundamentais para a garantia do contrarreferenciamento. $A$ chamada contrarreferência personalizada efetiva-se quando é pensada exclusivamente para aquele usuário, seguindo e baseando-se em suas demandas singulares.

A Portaria $n^{0}$ 1.820, de 13 de agosto de 2009 dispõe sobre os direitos e deveres dos usuários da saúde. O presente documento foi elaborado de acordo com seis princípios basilares que, juntos, asseguram ao cidadão o direito básico ao ingresso digno nos sistemas de saúde, sejam eles públicos ou privados. (BRASIL, 2011). 
1. Todo cidadão tem direito ao acesso ordenado e organizado aos sistemas de saúde; 2. Todo cidadão tem direito a tratamento adequado e efetivo para seu problema; 3. Todo cidadão tem direito ao atendimento humanizado, acolhedor e livre de qualquer discriminação; 4 . Todo cidadão tem direito a atendimento que respeite a sua pessoa, seus valores e seus direitos; 5. Todo cidadão também tem responsabilidades para que seu tratamento aconteça da forma adequada; 6 . Todo cidadão tem direito ao comprometimento dos gestores da saúde para que os princípios anteriores sejam cumpridos. (BRASIL, 2011).

A Rede de Atenção à Saúde, como o conjunto de ações e serviços de saúde articulados em níveis de complexidade crescente, têm a finalidade de garantir a integralidade da assistência à saúde, mediante referenciamento do usuário na rede regional e interestadual, conforme pactuado nas Comissões Intergestores. E é justamente na questão do referenciamento do usuário na rede que se sustenta uma personalização e um olhar individual para cada contrarreferência (MENDES, 2011).

\section{CONCLUSÃO}

Neste estudo foi possível visualizar o processo de construção de um fluxograma de contrarreferenciamento cujo qual teve como objetivo a responsabilização e corresponsabilização da equipe multiprofissional para a efetivação de tal proposta. Diante a isto, cabe refletir sobre o encadeamento de compromissos e rotinas para a manutenção e a garantia de um cuidado integral à saúde do usuário respeitando os pontos, dispositivos de saúde e da rede de cada território com as suas singularidades e particularidades.

As reflexões desta pesquisa permitem reforçar a necessidade em desenvolver estudos de caráter avaliativo e educativo para qualificar os processos e instrumentos de trabalho tais como o fluxograma de contrarreferenciamento no contexto hospitalar. Assim como, a necessidade de conexão dos pontos da rede, que se fazem a partir dos profissionais de saúde, o compartilhamento de documentos e de informações acerca do adoecimento do usuário para que outro profissional, em outro ponto da rede possa garantir um cuidado qualificado, oportuno e resolutivo para a situação problema de saúde do usuário. 


\section{QUFN}

\section{REFERÊNCIAS}

BRASIL. Ministério da Saúde. Carta dos direitos dos usuários da saúde / Ministério da Saúde. - 3. ed. - Brasília : Ministério da Saúde, 2011.

BRASIL. Conselho Federal de Psicologia. Referências técnicas para atuação de psicólogas(os) nos serviços hospitalares do SUS / Conselho Federal de Psicologia, Conselhos Regionais de Psicologia e Centro de Referência Técnica em Psicologia e Políticas Públicas. —— 1. ed. _— Brasília : CFP, 2019.

GIL, A. C. Como elaborar projetos de pesquisa. 6ª ed. São Paulo: Atlas, 2018.

MENDES, E. V. As redes de atenção à saúde. / Eugênio Vilaça Mendes. Brasília: Organização pan-americana da saúde, 2011. 


\section{ANEXO 1}

\section{•ํำ \\ Camivite de Edurecela. \\ Pesmenerte e Contibasesta \\ FLUXOGRAMA DE CONTRARREFERÊNCIA \\ HOSPITAL CASA DE SAÚDE \\ Unidade Santa Clara}

\begin{tabular}{lrr|} 
Médico & \multicolumn{2}{r}{ preenche } \\
diariamente a planilha de \\
PREVISÃo DE $\quad$ ALTA \\
CLÍNICA, com $\quad$ data \\
prevista, e serviços que irá \\
realizar \\
encaminhamentos.
\end{tabular}

A PLANILHA DE PREVISÃO DE ALTA, deverá ser compartilhada com $\circ$ enfermeiro de referência da Unidade Santa Clara diariamente.

Enfermeiro(a) recebe, as vias, verifica se está devidamente preenchido e agendado e faz a divisão das contrarreferencias.
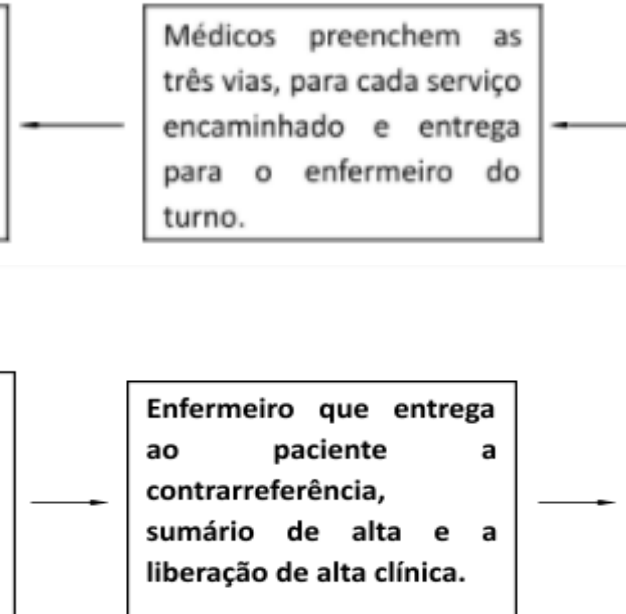

3a via: Do prontuário
Obs.: Todos os profissionais que atuam na Unidade Santa Clara deverão ter ciencia e respeitar este fluxo.

- Não se pode dar alta para o paciente sem que esteja efetivado os agendamentos e registrados na contrarreferencia;

- No ato da alta também deverá ser disponibilizado o sumário de alta pelo médico;

- A previsão de alta hospitalar deverá ser comunicada com no mínimo $\mathbf{4 8}$ horas de antecedência de sua efetivação.
Residentes, André, conforme escala, fazem o envio de e-mail para as UBS, ESF, serviços de saúde para formalizar o contrareferenciamento.
Enfermeiro compartilha com a dupla de residentes da semana para que os agendamentos possam serem efetivados.

\section{Residentes/André,} agendam e devolvem ao médico a data, hora do agendamento para personalização da contrarreferencia.

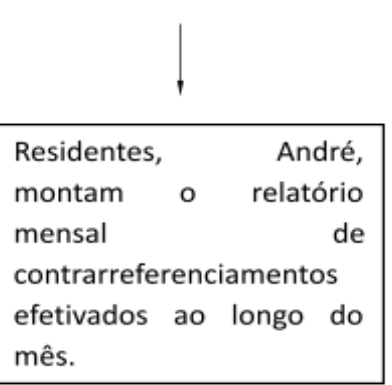


EDUCAÇÃO, SAÚDE

ETECNOLLOGIA

26 A 28 DE OUTUBRO DE 2021

\section{QUFN}

\section{ANEXO 2}

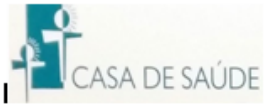

HOSPITAL CASA DE SAÚDE EQUIPE DE CONTRARREFERENCIA

TABELA DE PLANEJAMENTO DE ALTA HOSPITALAR

ROUND DA EQUIPE DO DR

DATA: $\_\_/ 2021$

\begin{tabular}{|c|c|c|c|c|c|}
\hline NOME DO PACIENTE & CID & \begin{tabular}{|c|} 
DATA DA \\
PEVVISAO \\
DAALTA
\end{tabular} & $\begin{array}{l}\text { UBSESFAAMBULATORIOe } \\
\text { OUTROS }\end{array}$ & $\begin{array}{l}\text { DoNTATDO COM } \\
\text { QUEMFALOU } \\
\text { QUEMFIOU }\end{array}$ & $\begin{array}{l}\text { AGENDADO } \\
\text { PARA: }\end{array}$ \\
\hline & & & & & \\
\hline & & & & & \\
\hline & & & & & \\
\hline & & & & & \\
\hline & & & & & \\
\hline & & & & & \\
\hline & & & & & \\
\hline & & & & & \\
\hline & & & & & \\
\hline & & & & & \\
\hline & & & & & \\
\hline
\end{tabular}

